\title{
PERANCANGAN SISTEM INFORMASI PADA DIVISI CAD PT. YONGJIN JAVASUKA GARMENT DENGAN METODE WATERFALL
}

\author{
Agung Alan Saputra ${ }^{a}$, Muhamad Muslih \\ ${ }^{a, b}$ Program Studi Sistem Informasi, Universitas Nusa Putra, Jawa Barat \\ aagung.alan_si17@nusaputra.ac.id, bmuhammad.muslih@nusaputra.ac.id,
}

\begin{abstract}
ABSTRAK
Kabupaten sukabumi memiliki berbagai perusahaan industri atau garment yang tersebar di beberapa wilayah. Salah satunya adalah PT. Yongjin Javasuka Garment yang terletak di kecamatan cicurug dapat menopang laju perekonomian warga sekitar dengan membuka lapangan pekerjaan sebagai karyawan buruh. Dalam dunia garment ternyata banyak organisasi yang aktif di setiap bidangnya. Adapun CAD merupakan divisi yang bekerja sebagai peran pendukung untuk melancarkan proses produksi dari awal sampai akhir. Untuk pekerjaanya CAD memiliki beberapa bagian yang berbeda-beda yaitu seorang pattern maker, marker, plot pattern dan plot marker. Ketika bekerja semuanya saling berinteraksi dan berhubungan. Dengan melalui jaringan internet semua komputer dapat mengakses data satu sama lain. Namun pada praktek lapangannya kini masih terdapat kendala yang seharusnya di evaluasi. Data yang diberikan dari pihak karyawan satu ke karyawan yang lain masih ada yang bersifat manual. Hal ini menyebabkan pekerjaan menjadi lambat sehingga tidak maksimal. Pada kasus diatas maka dibutuhkan suatu sistem yang dapat menampung sebuah data dengan layanan internet untuk memaksimalkan fasilitas perusahaan tersebut. Oleh karena itu pada penelitian ini digunakan metode waterfall untuk memberikan kemudahan bagi karyawan dalam mengakses data.
\end{abstract}

Kata Kunci : $C A D$, garment, sistem informasi, waterfall

\begin{abstract}
Sukabumi Regency has various well-known industrial or garment companies in several regions. One of them is PT. Yongjin Javasuka Garment, which is located in the cicurug sub-district, can support the economic pace of local residents by opening up jobs as laborers. In the world of garment, there are many organizations that are active in every field. The CAD is a division that works as a support role to streamline the production process from start to finish. For CAD work has several different parts, namely a pattern maker, marker, plot pattern and plot marker. When working are interconnected. Through the internet, all computers can access each other's data. However, in practice, there are still restrictions that should be evaluated. Data provided from one employee to another is still manual. This causes work to be slow so that it is not optimal. In the above case, we need a system that can store data with internet services to maximize the company's facilities. Therefore, this study uses the waterfall method to make it easier for employees to access data.
\end{abstract}

Keywords : CAD, garments, Information Systems, Waterfalls

\section{PENDAHULUAN}

Perkembangan dunia teknologi saat ini sangat pesat seiring dengan peningkatan kebutuhan layanan yang cepat dan efsien.
Pada suatu kegiatan usaha seperti sebuah perusahaan sangat membutuhkan sumber daya manusia yang mampu memanfaatkan teknologi sebagai alat untuk menopang 
kualitas maupun produktivitas usaha tersebut. Dalam hal ini, kita menyadari sistem informasi merupakan modal utama dalam kegiatan tersebut.

PT. Yongjin Javasuka Garment merupakan perusahaan induk dari kelompok usaha di Indonesia yang bergerak di bidang tekstil dan garment untuk wilayah domestik dan internasional. Salah satu kegiatan usahanya yaitu membuat ide yang menghasilkan konsep fashion dan design terbaru secara keseluruhan. Berkembang seiring dengan waktu dan mengikuti perkembangan jaman untuk mengantisipasi trend dimasa yang akan datang. Tentunya peran teknologi sangat dominan dalam menentukan keberhasilan dan merupakan salah satu kebutuhan pokok.

Sebagai perusahaan yang maju tentu saja hal ini berkaitan dengan sistem yang baik dan terintegrasi. Oleh karena itu, sistem informasi menjadi salah satu kunci keberhasilan dalam aktifitas pekerjaanya. Kemudian sebagai perusahaan juga harus dapat memberikan pelayanan dan memberikan fasilitas terbaik bagi konsumen maupun karyawannya. Suatu perusahaan harus dapat menyediakan fasilitas informasi dan komunikasi dengan cepat, tepat, dan akurat. Sehingga hasil usahanya menjadi maksimal. Akan tetapi dalam hal ini permasalahan praktek lapangannya selalu menjadi kendala dan hambatan dalam pengembangan di setiap organisasi atau departemen.

Saat ini pada dunia garment ternyata banyak organisasi yang aktif di setiap bidangnya. Adapun CAD merupakan divisi yang bekerja sebagai peran pendukung untuk melancarkan proses produksi dari awal sampai akhir. Dalam pekerjaannya divisi ini mempunyai empat bagian yang terpisah yaitu pattern maker, marker, plot pattern dan plot marker. Ketika bekerja semuanya saling berinteraksi dan berhubungan. Dengan melalui jaringan internet semua komputer dapat mengakses data satu sama lain. Namun pada praktek lapangannya kini masih terdapat kendala yang seharusnya di evaluasi. Data yang diberikan dari pihak karyawan satu ke karyawan yang lain masih ada yang bersifat manual. Oleh karena itu dari permasalahan ini penulis tertarik untuk melakukan penelitian dalam bidang sistem informasi pada perusahaan tersebut.

\section{METODE PENELITIAN}

\section{A. Alat}

Alat yang digunakan dalam penelitian ini berupa komputer yang tersedia dari perusahaan tersebut, kemudian fasilitas alat tulis kantor, jaringan internet dan beberapa aplikasi atau website yang mendukung untuk pembuatan design.

\section{B. Bahan}

Adapun data sebagai bahan yang dibutuhkan dalam menyelesaikan penelitian ini adalah hasil dari observasi itu sendiri. Serta diluar lingkungan pekerjaan mendapatkan data tambahan yang di dapatkan dari berbagai jurnal dan artikel di internet sebagai referensi penelitian.

\section{Sumber Data \\ 1) Data Primer}

Dalam penelitian ini, data primer yang didapat berupa hasil observasi dan hasil wawancara dengan karyawan perusahaan.

\section{2) Data Sekunder}

Data sekunder diperoleh dengan cara membaca referensi dari jurnal-jurnal yang berkaitan dengan hal-hal yang akan diteliti.

D. Metode Pengumpulan Data

1) Metode Observasi

Merupakan teknik pengumpulan data, dimana peneliti melakukan pengamatan ke 
objek penelitian untuk melihat dan merasakan kegiatan yang dilakukan secara langsung.[1]

\section{2) Metode Studi Pustaka}

Teknik pengumpulan data yang dilakukan dengan menelaah dan mempelajari beberapa literatur yang terkait dengan judul atau masalah yang akan dikaji. Dalam penelitian ini cara yang digunakan menggunakan beberapa teori-teori yang sudah ada. Selain itu jurnal, serta buku-buku dan referensi web lain yang berkaitan dengan masalah penelitian.[2]

\section{3) Metode Wawancara}

Wawancara adalah proses memperoleh informasi dengan cara tanya jawab antara si peneliti dengan objek penelitian sambil bertatap muka secara langsung. Biasanya dalam proses wawancara ini peneliti hendak memastikan fakta, dan memperkuat data.[3]

E. Tahap Penelitian

1) Analisis

Proses analisa atau pengumpulan data-data yang berkaitan dengan sistem yang akan dirancang. Dalam tahap ini hal pertama yang dilakukan adalah dengan terjun langsung ke lapangan atau melakukan observasi mengikuti segala aktifitas dan kegiatan karyawan sambil dengan wawancara.

\section{2) Desain}

Proses yang berfokus pada pembangunan struktur data, perancangan interface, arsitektur dan perangkat lunak. Serta fungsi internal dan eksternal dari setiap algoritma secara detail. Pada tahap ini ditambahkan juga desain menggunakan use case diagram, activity diagram dan class diagram.

\section{3) Implementasi (pengerjaan)}

Tahap ini adalah proses pengerjaan dan pembuatan aplikasi oleh para programmer dengan menggunakan kode-kode bahasa pemrograman tertentu (coding).

\section{4) Pengujian}

Berfokus pada hasil perangkat lunak yang telah dibuat. Kemudian dilakukan pengujian dari segi logic dan fungsional memastikan bahwa semua bagian sudah diuji. Hal ini dilakukan untuk meminimalisir kesalahan (error) dan memastikan sistem apakah sesuai dengan yang diinginkan.

5) Pendukung (support) dan Pemeliharaan (maintenance)

Fase ini terjadi setelah akhir dari proses pengujian dan disetujui oleh pelanggan. Kemudian maintenance adalah proses memperbaiki sistem dari setiap kesalahan (error atau bug), memperkuat keamanan dan peningkatan kinerja serta memastikan aplikasi dapat berjalan sesuai dengan design yang telah dirancang.



Gambar 1. Tahapan penelitian [4]

\section{HASIL DAN PEMBAHASAN}

\section{A. Pengumpulan Data}

Penelitian ini dilakukan secara bersakala dengan mengikuti segala kegiatan dan aktivitas kerja bersama karyawan di perusahaan tersebut. Selain itu diluar dari perusahaan, penulis juga mencoba mengumpulkan data dari berbagai sumber yaitu seperti pada jurnal-jurnal, website di internet dan beberapa orang-orang yang terkait dibidangnya.

B. Pengolahan Data

Data yang telah didapatkan kemudian diolah untuk mengetahui hasil selama 
penelitian. Pada tahap ini akan didapatkan berupa rancangan sistem yang nantinya akan di aplikasikan pada tahap selanjutnya dengan metode waterfall berupa gambaran menggunakan use case diagram, activity diagram dan class diagram.

\section{Sample Data}

Data yang dikumpulkan berupa hasil observasi dan wawancara yang dilakukan kepada karyawan perusahaan dengan jumlah sampel sebanyak 41 orang acak. Total tersebut merupakan jumlah karyawan pada divisi CAD baik itu seorang adm, pattern dan marker.

Kemudian data yang dibutuhkan dalam desain sistem informasi ini antara lain data $a d m$, data pattern dan data marker. Untuk lebih detailnya antara lain: bill of material, material sheet, schedule, down schedule, data email, microsof office (Microsoft word, Microsoft excel, Microsoft power point), PDF, optitex PDS pattern, optitex MRK marker, DXF \& RUL, Gerber pattern, Lectra pattern, Gerber marker, Lectra marker, PLT, corel draw, Adobe illustrator (AI), JPEG, $\mathrm{PNG}$, all images format.

\section{Rancangan Sistem Usulan}

a) Tahapan Analisis

Halaman Adm antara lain:

- Adm harus login

- Adm masuk ke beranda

- Adm dapat mengelola $(a d d)$ data pattern

- Adm dapat mengelola $(a d d)$ data marker

- Adm dapat mengelola (add, create, edit, rename, delete) data lain-lain

Halaman pattern antara lain:

- Pattern harus login

- Pattern menegelola data pattern
- Pattern dapat merubah (edit) data pattern

- Pattern dapat mengganti (rename) data pattern

- Pattern dapat menghapus (delete) data pattern

- Pattern dapat menyimpan (save as) data pattern

Halaman Marker antara lain:

- Marker harus login

- Marker dapat mengelola data marker

- Marker dapat merubah (edit) data marker

- Marker dapat mengganti (rename) data marker

- Marker dapat menghapus (delete) data marker

- Marker dapat meyimpan (save as) data marker

E. Desain

Pada tahap ini peneliti mencoba untuk membuat gambaran dalam melanjutkan hasil dari analisis tersebut. Namun hanya menggunakan tiga diagram saja, yaitu use case diagram, activity diagram dan class diagram.

Alur sistem ini dirancang berdasarkan hasil dari wawancara dengan karyawan. Menurut mereka desain yang akan dibuat ini cukup untuk memenuhi segala kebutuhan dan aktivitas karyawan. Begitupun dengan data akses yang sengaja di pisahkan. Walaupun admin, pattern dan marker berada dalam satu ruangan atau ruang lingkup, tetapi untuk data pengerjaanya berbeda-beda. Sebelumnya memang untuk penyimpanan data ini secara keseluruhan semua user dan anggota full akses dapat membuka secara masing-masing. Hanya saja masih terdapat kendala yang seharusnya di evaluasi, sehingga hal ini perlu ditingkatkan dan dikembangkan lebih lanjut agar dapat menjadi lebih baik.

1) Use Case Diagram 


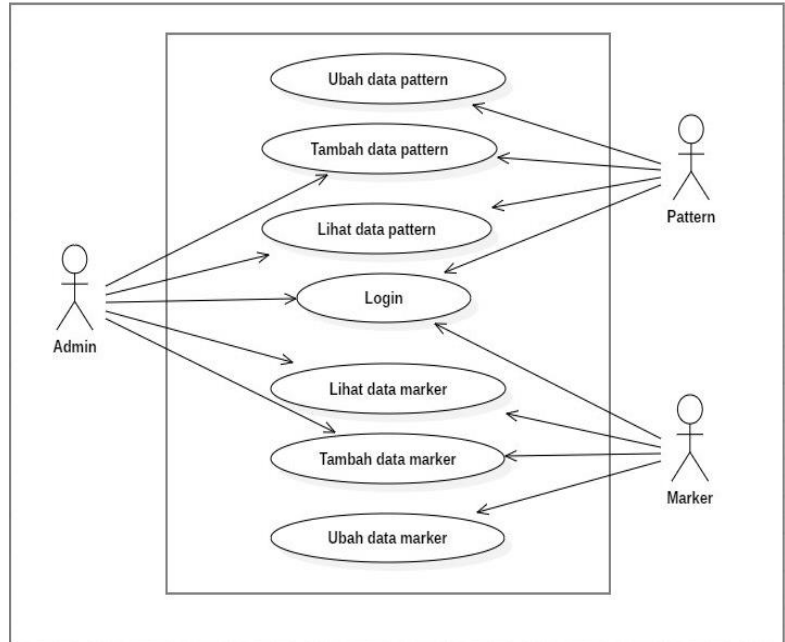

Gambar 2. Perancangan alur sistem pada use case diagram

2) Activity Diagram

a) Login User

Sistem kerja user antara lain:

- Start

- Login

- Input username dan password

- Membuka halaman utama user

- End

Sedangkan sistem akan membaca dan memproses:

- Validasi username dan password

- Benar atau tidak (ya \& tidak)

- Login berhasil



Gambar 3. Perancangan sistem login user b) Tambah Data

Sistem kerja user antara lain:

- Start

- Form tambah data

- Input form data

- Menampilkan data di halaman kelola data

- End

Sedangkan sistem akan membaca dan memproses:

- Validasi inputan data pada form

- Sesuai (ya \& tidak)

- Menyimpan data ke database

- Data tersimpan di database

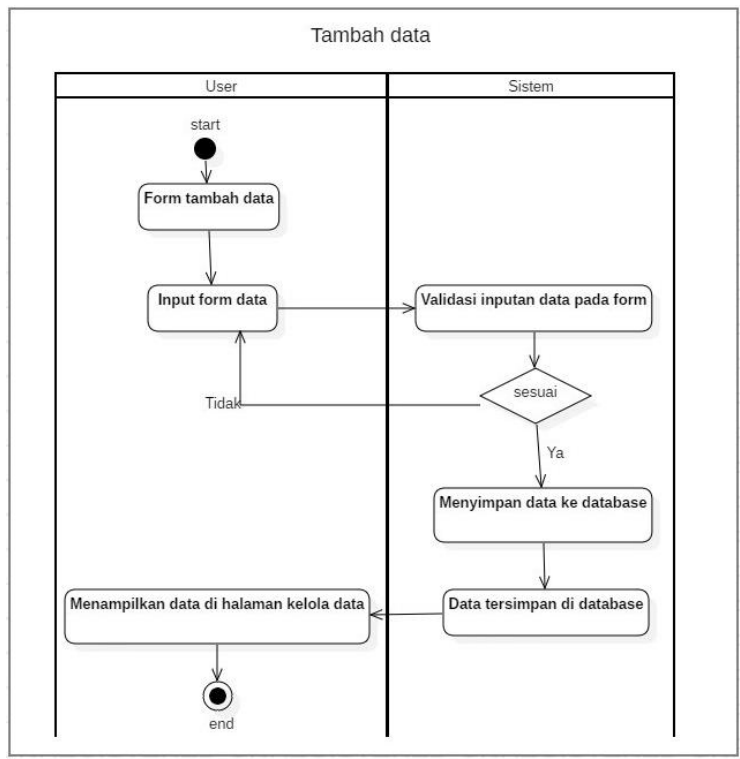

Gambar 4. Perancangan sistem untuk tambah data

c) Ubah Data

Sistem kerja user antara lain:

- Start

- Pilih data yang akan di ubah

- Form ubah data

- Input form ubah data

- Menampilkan data di halaman kelola data

- end

Sedangkan sistem akan membaca dan memproses: 
- Validasi data di data base dari inputan data

- Sesuai (ya \& tidak)

- Menyimpan perubahan data ke database

- Data perubahan tersimpan di database

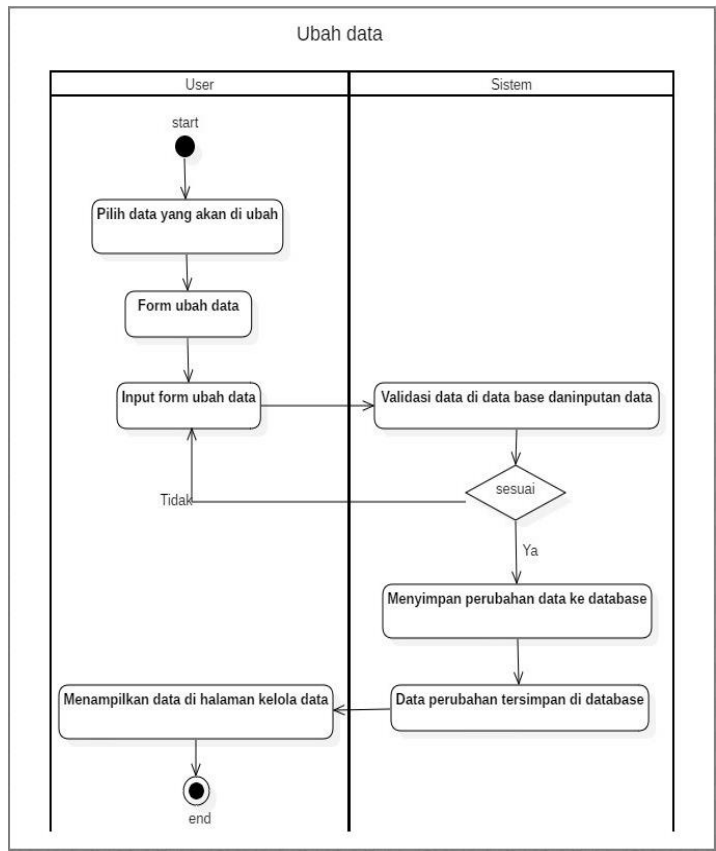

Gambar 5. Perancangan sistem untuk merubah data

d) Hapus Data

Sistem kerja user antara lain:

- Start

- Pilih data yang akan dihapus

- Menampilkan data di halaman kelola data

- End

Sedangkan sistem akan membaca dan memproses:

- Menghapus data di database

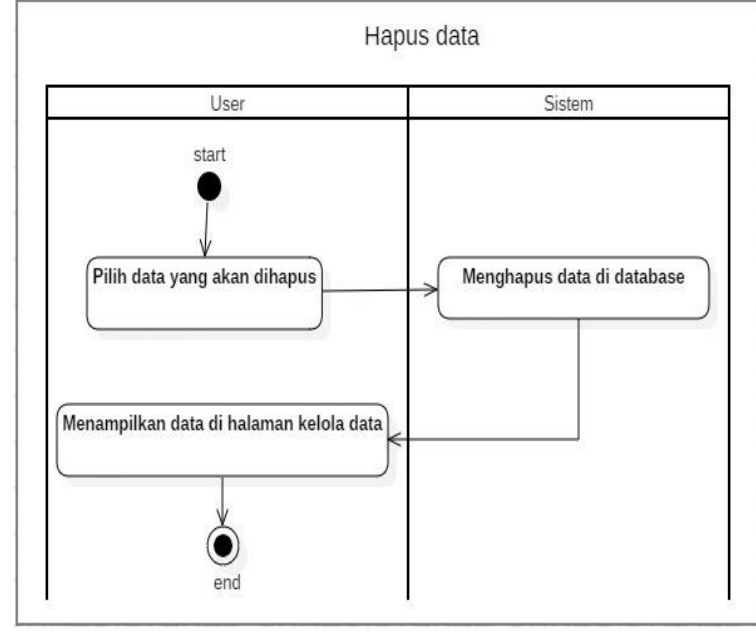

Gambar 6. Perancangan sistem untuk menghapus data

3) Class Diagram

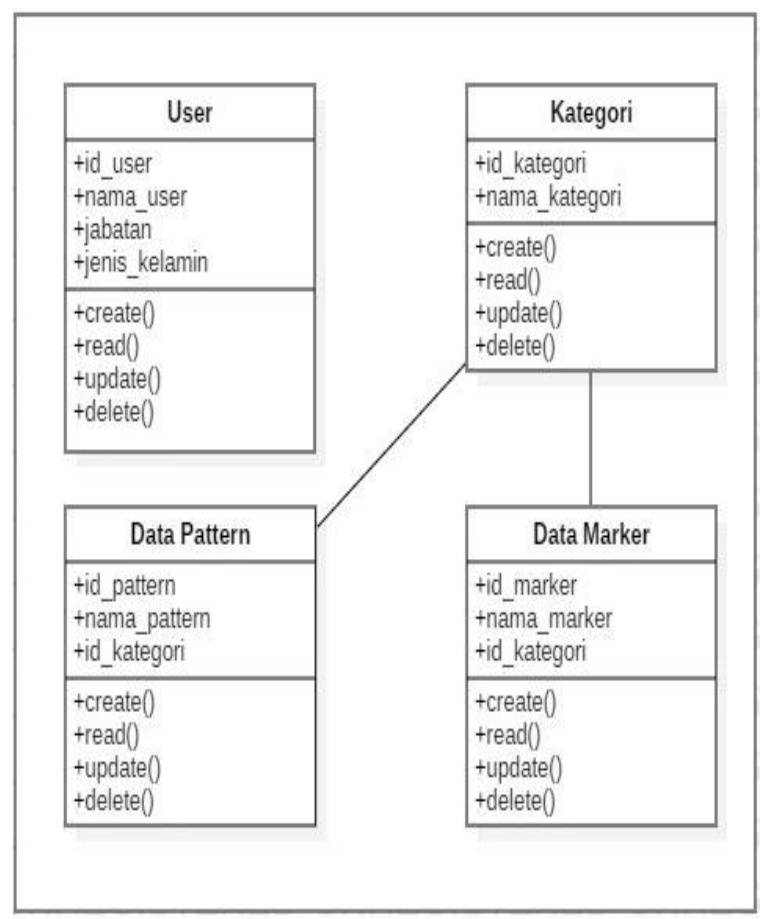

Gambar 7. Class Diagram

F. Implementasi (Pengerjaan)

Pada saat proses pengerjaan peneliti mencoba untuk membuatkan sistem berupa desain berbentuk halaman web. Tetapi sistem ini masih bersifat simulasi serta dalam tahap pengembangan sebagai lanjutan.

\section{1) Design Login}

- Pertama, user harus mengisi kolom NIK. 
- Kedua, user harus mengisi kolom PASSWORD.

- Ketiga, user harus memilih button sesuai jabatan masing-masing

- Keempat, login

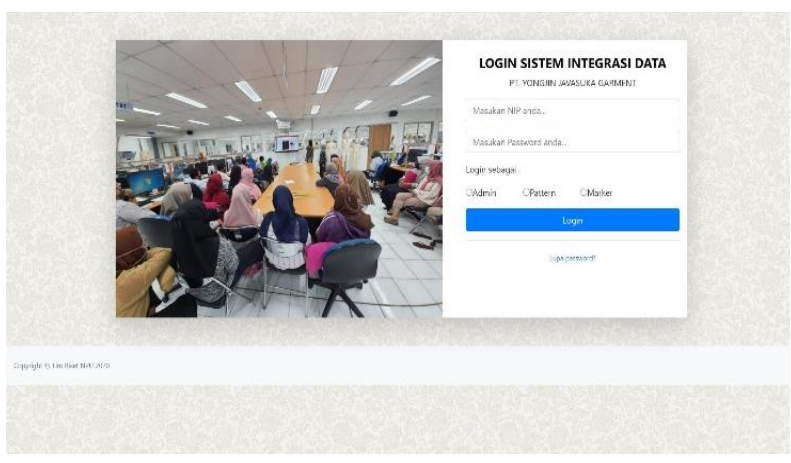

Gambar 8. Halaman login

2) Halaman Dashboard pada Admin

Setelah melakukan login pada halaman pertama user akan diperlihatkan tampilan dashboard oleh sistem. Untuk tampilan ini $a d m$ dapat mengelola serta menambahkan data pattern dan data marker. Tetapi adm tidak dapat merubah, data pattern dan data marker.

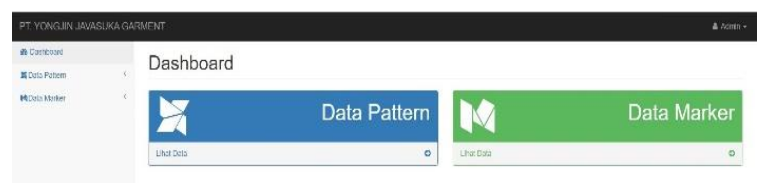

Gambar 10. Halaman dashboard pattern

4) Halaman Dasboard pada Marker

Sama halnya dengan dashboard pattern, hanya saja pada halaman ini user akan diperlihatkan dashboard data marker. Sebagai tambahan agar menjadi lebih mudah peneliti juga mencoba untuk membuat menu dibagian atas kiri.

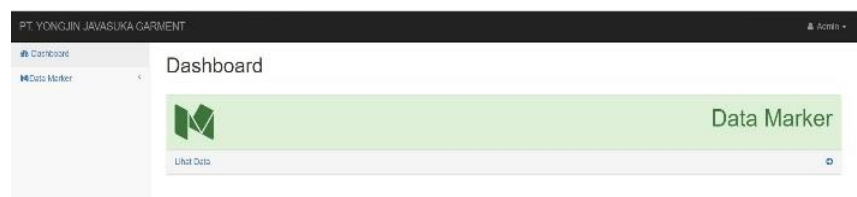

\section{Gambar 11. Halaman dashboard marker}

5) Halaman data pattern



Gambar 12. Halaman data pattern

6) Halaman data marker 


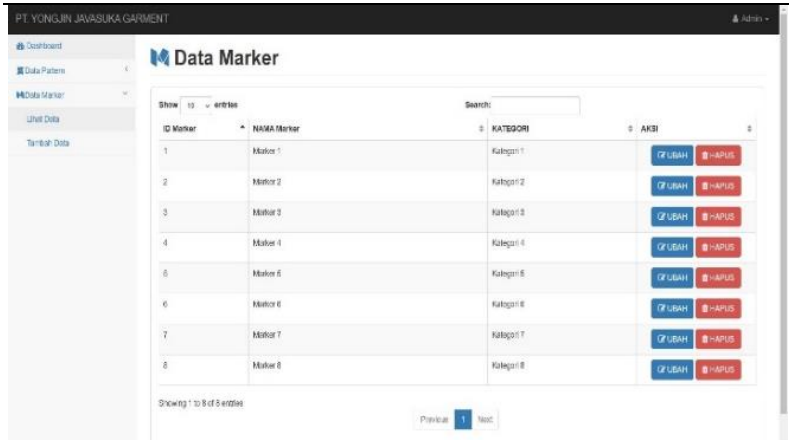

Gambar 13. Halaman data marker

\section{7) Halaman logout}

Untuk halaman logout dari setiap user dapat di klik pada menu bagian atas kanan. Dibawah tombol user profile dan setting.

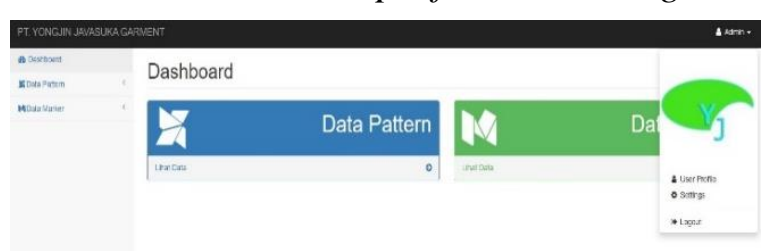

Gambar 14. Tampilan logout ada dibagian atas kanan

\section{G. Pengujian}

Ketika proses pengujian peneliti mencoba untuk membuatkan sistem berupa desain yang berbentuk halaman web. Tetapi sistem ini masih bersifat simulasi serta dalam tahap pengembangan sebagai lanjutan. Modul ini diintegrasikan dengan menggerakkan arah dari atas ke bawah melalui hirarki kontrol yang dimulai dari modul menu utama.[5]



Gambar 15. Alur integrasi sistem
Tahapan yang terakhir adalah pengoperasian dan perbaikan dari sistem tersebut. Setelah dilakukan pengujian, maka akan masuk pada tahap pemakaian perangkat lunak oleh pengguna (user). Sedangkan untuk proses pemeliharaan, memungkinkan pengembang untuk melakukan perbaikan terhadap kesalahan yang ditemukan pada sistem setelah digunakan oleh user.[6]

\section{KESIMPULAN}

Berdasarkan penelitian yang telah dilakukan, dengan ini dapat diambil kesimpulan bahwa dengan perancangan dan desain metode waterfall ini diharapakan kedepannya sistem informasi pada divisi perusahaan menjadi lebih baik. Dalam pengolahan data menjadi lebih efektif dan efisien. Kemudahan akses untuk mendapatkan data (input dan output) menjadi lebih cepat dan mudah. Serta memaksimalkan fasilitas internet perusahaan dengan sebaik-baiknya demi kelancaran dan kenyamanan karyawan dalam bekerja. Walaupun sistem informasi ini masih dalam tahap perancangan, peneliti akan tetap mengembangkan sampai proses akhir hingga bisa digunakan untuk keperluan perusahaan.

\section{DAFTAR PUSTAKA}

[1] dosenpendidikan, "Observasi," 28/12/2020, 2020.

https://www.dosenpendidikan.co.id/ob servasi/ (accessed Feb. 14, 2021).

[2] M. S. Putra, Purwa Hasan, Novelan, "Perancangan Aplikasi Sistem Informasi Bimbingan Konseling Pada Sekolah Menengah Kejuruan," J. Teknovasi, vol. 07, no. 01, pp. 1-7, 2020.

[3] Perpusku, "Metode Pengumpulan Data dengan Metode Wawancara (Interview)," Juni 2016, 2016. https://www.perpusku.com/2016/06/m etode-pengumpulan-data-denganmetode-wawancara-interview.html 
(accessed Feb. 14, 2021).

[4] J. Dermawan and S. Hartini, "IMPLEMENTASI MODEL

WATERFALL PADA

PENGEMBANGAN BERBASIS

WEB PADA SEKOLAH DASAR

AL-AZHAR SYIFA BUDI

JATIBENING," vol. 19, no. 2, 2017.

[5] G. Wiro Sasmito, "Penerapan Metode Waterfall Pada Desain Sistem

Informasi Geografis Industri

Kabupaten Tegal," J. Inform.

Pengemb. IT, vol. 2, no. 1, pp. 6-12, 2017.

[6] M. R. Adani, "Tahapan

Pengembangan Perangkat Lunak

dengan Metode Waterfall," Desember 29, 2020.

https://www.sekawanmedia.co.id/met ode-waterfall/ (accessed Feb. 14,

2021). 